\title{
Magnetic Stirrer with Speed Advisor and Timer Based on Microcontroller
}

\author{
I Made Agus Mahardiananta ${ }^{1}$, I Made Aditya Nugraha ${ }^{2 *}$, Putu Agus Mahadi Putra ${ }^{3}$, I Gede Sura Adnyana ${ }^{4}$ \\ ${ }^{1,4}$ Department of Electromedical Engineering, Bali International University, Bali, Indonesia \\ ${ }^{2}$ Fisheries Mechanization, Marine and Fisheries Polytechnic of Kupang, Nusa Tenggara Barat, Indonesia \\ ${ }^{3}$ Electronic Engineering Polytechnic Institute of Surabaya, East Java, Indonesia \\ Email: ${ }^{1}$ agusmahar28@yahoo.com, ${ }^{2}$ made.nugraha@kpp.go.id, ${ }^{3}$ mahadi@pens.ac.id, ${ }^{4}$ suraadnyana46@ gmail.com \\ *Corresponding Author
}

\begin{abstract}
Magnetic stirrer is a laboratory tool used to stir or mix a solution with other solutions so that the solution is homogeneous. The existing magnetic stirrers are only equipped with a mixer speed regulator using an analog control knob. Technology and science have now progressed, so in this study a microcontroller based magnetic stirrer was designed. This tool is designed with digital speed and time settings, so that it is expected that errors from reading the speed and time of mixing the samples can be expected. The results of the homogeneity of the solution were carried out with 11 types of solutions from low to high viscosity levels. Testing the solution with a low viscosity level using $100 \mathrm{ml}$ water with $40 \mathrm{ml}$ syrup. For solutions 2 and 3 , namely Water $100 \mathrm{ml}$ with $20 \mathrm{ml}$ and $40 \mathrm{ml}$ special grade syrup. For a solution of 4,5,6 and 7, namely $100 \mathrm{ml}$ air with $2.5 \mathrm{gr}, 3.5$ gr, 6.5 gr, and 10 gr salt. For solutions 8, 9, 10 and 11, namely water $100 \mathrm{ml}$ with sugar $2.5 \mathrm{gr}, 3.5 \mathrm{gr}, 6.5 \mathrm{gr}$, and $10 \mathrm{gr}$. Based on the results of the analysis that has been carried out on a solution with low viscosity, it takes 1 minute of mixing at low, medium and high speeds. For a solution with a higher viscosity it takes 5 minutes at medium and high speeds. Mixing air with salt and air with sugar takes $\mathbf{1 0}$ minutes at high speed.
\end{abstract}

\section{Keywords-Laboratory Equipment, Magnetic Stirrer,} Microcontroller

\section{INTRODUCTION}

The laboratory is a place for conducting experiments and research. The laboratory is also a place to train students and for students in practical skills, demonstrations, experiments, research, and scientific development. Laboratory referred to her does not only mean a room or a building used for scientific experiments, for example in the fields of science, biology, chemistry, physics, engineering, and so on. Where the laboratory is also a place for scientific activities in the form of experiments, research, observation, demonstrations related to teaching and learning activities [1][2][3][4][5][6].

A solution is a homogeneous mixture of two or more substances that dissolve each other and the respective constituent substances cannot be distinguished physically. The solution consists of a solute and a solvent. Based on the electrical conductivity (ionization power), there are two kinds of solutions, such as electrolyte solutions and non-electrolyte solutions. Electrolyte solution is a solution that can conduct electric current. This solution is divided into strong electrolytes and weak electrolytes [7].

The analysis of a particular liquid sample requires additional substances or liquids or mixers that can help the analysis process. Liquid additives or mixers are often referred to as reagents. Reagents are substances that are added in order to bring or induce a change reaction [8][9][10]. The mixture of the analytical samples must be perfect (homogeneous), so a mixer is needed to assist the mixing [11][12]. The tools used in the stirring or mixing process are expected to produce well mixed (homogeneous) samples. Manual mixing often results in poor samples because each sample has a different mixing time and speed.

Magnetic stirrer is a laboratory tool used to mix or mix a solution with another so that the solution is homogeneous [13][14][15]. The current magnetic stirrer is only equipped with a diverter speed controller using an analog control knob [16][17][18][19]. The laboratory assistant or user uses a stopwatch or time estimate to determine the stirring time of a sample. The weakness of this technology is inaccurate precision and accuracy.

The research that has been done, entitled Design of a Magnetic Stirrer with Setting the Speed of the Stirrer and the Setting of the Stirring Time. The design of a magnetic stirrer with a stirring speed and time setting that has been made can work stirring the sample at a speed of up to $3000 \mathrm{Rpm}$ with a stirring time from 1 minute to 60 minutes. In the experiment, using a sample of a mixture of water with a syrup solution, a mixture of water with a solution of food coloring, and a mixture of soapy water and cooking oil. The three samples can be mixed as expected. Similar research is about the study of a magnetic based stirrer system and fluid heating using a microcontroller. In the stirrer test, it is carried out by rotating the fluid solution with different viscosities and obtaining the fluid rotation velocity value, while in the heating test, it is carried out by heating the fluid solution with different viscosities and monitoring changes in fluid temperature. Based on the calculation of the results of the stirring test data after entering the formula, the error varies greatly, so that the fluid rotation method with a stirrer cannot measure the viscosity of a solution.

Technology and science have now progressed, so in this study a microcontroller based magnetic stirrer was designed. This tool is designed with digital speed and time settings. With digital technology, it is expected that errors from reading the speed and time of mixing samples can be minimized, efficient in terms of time, relatively easier to use and produce a homogeneous solution. 


\section{METHODS}

This research is a research development or Research and Development (R\&D). This research is developing and is one type of research that can be a link or break the gap between basic research and applied research. The definition of Research and Development (R\&D) is often defined as a process or steps to develop a new product or improve an existing product.

In the purpose of this development research contains two information. First is to solved the problem and secondly is for learning specifications, model, problem, or device that will be produced to solve the problem. It can be argued that the aim of development research is to inform the decision making process as long as the development of a product develops and the developer's ability to create things of this type in future situations. Its purpose is to enhance the instructional design, development, and evaluation process that is based on other specific problem solving situations or generalized examination procedures.

The object of this research is a magnetic stirrer device. The way of observation is by direct measurement of the tool by observing using the observation guide. In this case, the time set on the analog magnetic stirrer will be compared with the time set on the microcontroller based magnetic stirrer. In addition, tests will also be carried out in the laboratory of the results of the mixing of the samples used.

In this research, using several tools, such as a multimeter, solder, pliers, cutter and screwdriver. Multimeters are used to measure currents and voltages when making tools [20][21]. Solder is used to solder electronic components in making tools. Pliers, cutters and screwdrivers are used as tools in making tools [22].

Several materials were used for the manufacture of tools, such as Arduino, infrared sensors, DC motors, LEDs, bussers, LCDs and other electronic components. Adunino is a microcontroller component used in making tools [23][24][25][26][27][28]. Infrared sensor is used to read motor speed (rpm). The DC motor is the driving force of this tool to stir the sample. LEDs are used as an indicator of an ongoing process. Bussser is an alarm that will sound as a sign that mixing or stirring has jam. LCDs and other electronic components as additional materials used in making tools [26][27][29][30][31].

Microcontroller based magnetic stirrer tool works with DC power supply at a voltage of $12 \mathrm{~V}$. The power supply supplies the entire circuit to the DC motor. This circuit works from providing speed options via a push button to the Arduino displayed on the LCD. The Arduino microcontroller gets a choice of speed. It will immediately provide PWM input to the motor driver to drive the motor according to the speed choice. The motor driver that has been inputted will not be able to rotate because it is disconnected by the timer circuit. The timer circuit is given a time setting input so that the tool works. After that the start button is pressed to trigger the timer circuit and activate the relay so that the timer circuit starts counting down, which indicates that the tool starts working. The magnet above the DC motor will rotate with the stir bar on the test glass. This happens because of the mutual attraction of the magnet with the stir bar. The timer information is displayed through the seven segment. Fig. 1 is a block diagram of a Microcontroller Based Magnetic Stirrer.

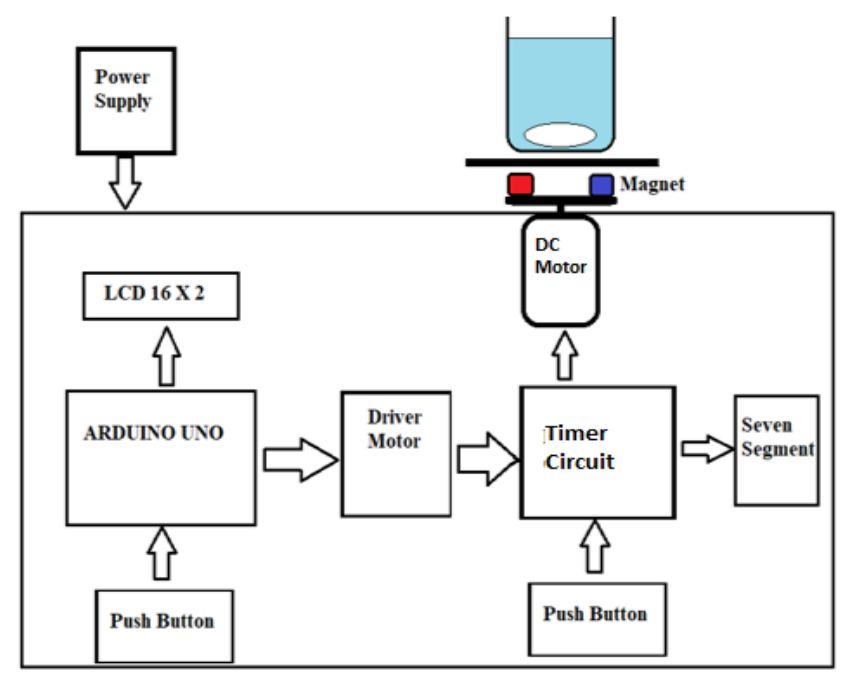

Fig. 1. Microcontroller Based Magnetic Stirrer Block Diagram

\section{RESULT AND DISCUSSION}

The manufacture of this tool uses a microcontroller to adjust the timer that works on the tool and the speed (rpm) of the tool when it is working. The timer set on this tool is set in seconds. This tool can run a maximum time of 999 seconds. This tool can also adjust the speed with three speed options, namely low (178.20 rpm), medium (233.00 rpm) and high (266.60 rpm). Fig. 2 is a microcontroller based magnetic stirrer that has been made.

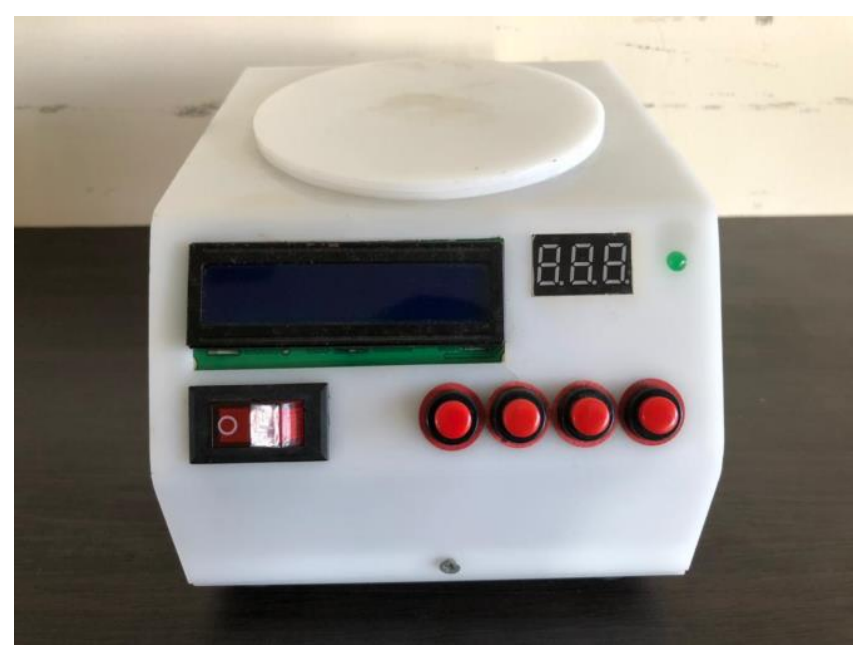

Fig. 2. Microcontroller Based Magnetic Stirrer

Magnetic stirrer was tested by mixing water with syrup, special grade syrup, salt and sugar. Stirring time is $1,5,10$ and 15 minutes. The microcontroller based magnetic stirrer homogeneity test was compared with the results of the mixture using an analog manufactured magnetic stricter. The microcontroller based magnetic stirrer work test is presented in Table 1. 
TABle I. Result of Microcontroller BAsed MAGNETiC StiRRER WORK TESTING

\begin{tabular}{|c|c|c|c|c|c|c|c|}
\hline No & Speed & Repeat & $\begin{array}{c}\text { Not } \\
\text { Burdened }\end{array}$ & $100 \mathrm{ml}$ & $150 \mathrm{ml}$ & $200 \mathrm{ml}$ & $250 \mathrm{ml}$ \\
\hline \multirow{5}{*}{1} & \multirow{5}{*}{ Low } & 1 & 2390 & 178 & 115 & 111 & 106 \\
\hline & & 2 & 2390 & 179 & 115 & 111 & 106 \\
\hline & & 3 & 2391 & 178 & 115 & 112 & 106 \\
\hline & & 4 & 2390 & 178 & 116 & 111 & 106 \\
\hline & & 5 & 2391 & 178 & 115 & 111 & 106 \\
\hline \multirow{5}{*}{2} & \multirow{5}{*}{ Medium } & 1 & 2870 & 233 & 211 & 198 & 189 \\
\hline & & 2 & 2871 & 233 & 211 & 198 & 188 \\
\hline & & 3 & 2870 & 233 & 211 & 199 & 189 \\
\hline & & 4 & 2869 & 233 & 210 & 198 & 189 \\
\hline & & 5 & 2870 & 233 & 211 & 197 & 189 \\
\hline \multirow{5}{*}{3} & \multirow{5}{*}{ High } & 1 & 3310 & 267 & 245 & 230 & 216 \\
\hline & & 2 & 3310 & 266 & 244 & 230 & 215 \\
\hline & & 3 & 3311 & 266 & 245 & 230 & 216 \\
\hline & & 4 & 3310 & 267 & 245 & 231 & 216 \\
\hline & & 5 & 3310 & 267 & 244 & 230 & 216 \\
\hline
\end{tabular}

This work test is carried out to determine the motor rotation in rpm at Low, Medium and High speed options. The results of testing the homogeneity of the solution using a microcontroller based magnetic stirrer and manufacturer's magnetic stirrer were obtained as shown in Table 2.

TABLE II. Solution HomogeneITy TEST RESUltS

\begin{tabular}{|c|c|c|c|}
\hline \multirow{2}{*}{ Speed } & \multirow{2}{*}{ Time (Minutes) } & \multicolumn{2}{|c|}{ Homogeneity of the Solution } \\
\hline & & Analog & Digital \\
\hline \multirow{4}{*}{ Low } & 1 & $\sqrt{ }$ & $\sqrt{ }$ \\
\hline & 5 & $\sqrt{ }$ & $\sqrt{ }$ \\
\hline & 10 & $\sqrt{ }$ & $\sqrt{ }$ \\
\hline & 15 & $\sqrt{ }$ & $\sqrt{ }$ \\
\hline \multirow{4}{*}{ Medium } & 1 & $\sqrt{ }$ & $\sqrt{ }$ \\
\hline & 5 & $\sqrt{ }$ & $\sqrt{ }$ \\
\hline & 10 & $\sqrt{ }$ & $\sqrt{ }$ \\
\hline & 15 & $\sqrt{ }$ & $\sqrt{ }$ \\
\hline \multirow{4}{*}{ High } & 1 & $\sqrt{ }$ & $\sqrt{ }$ \\
\hline & 5 & $\sqrt{ }$ & $\sqrt{ }$ \\
\hline & 10 & $\sqrt{ }$ & $\sqrt{ }$ \\
\hline & 15 & $\sqrt{ }$ & $\sqrt{ }$ \\
\hline
\end{tabular}

The homogeneity test of the solution was carried out with 11 types of solutions from low viscosity to high viscosity levels. Testing the low viscosity level solution using $100 \mathrm{ml}$ water with $40 \mathrm{ml}$ syrup. Solutions 2 and 3 are $100 \mathrm{ml}$ water with $20 \mathrm{ml}$ and $40 \mathrm{ml}$ special grade syrup. For solutions 4, 5, 6 and 7 , namely $100 \mathrm{ml}$ water with $2.5 \mathrm{gr}, 3.5 \mathrm{gr}, 6.5 \mathrm{gr}$, and $10 \mathrm{gr}$ salt. For solutions 8, 9, 10 and 11 , namely $100 \mathrm{ml}$ water with $2.5 \mathrm{gr}, 3.5 \mathrm{gr}, 6.5 \mathrm{gr}$, and $10 \mathrm{gr}$ sugar.
In this study, a comparative statistical calculation was carried out by comparing the two dependent groups (paired test) to the results of the microcontroller based magnetic stirrer test using the factory based magnetic stirrer using the SPSS program. The results of the Between Subjects Factors test are shown in Table 3.

TABLE III. BETWEEN SUBJECT FACTORS RESUlTS

\begin{tabular}{|c|c|c|c|}
\hline \multicolumn{2}{|c|}{ Factor } & Value Label & N \\
\hline \multirow{4}{*}{ Load } & 1.00 & Not Burdened & 15 \\
\cline { 2 - 4 } & 2.00 & $100 \mathrm{ml}$ & 15 \\
\cline { 2 - 4 } & 3.00 & $150 \mathrm{ml}$ & 15 \\
\cline { 2 - 4 } & 4.00 & $200 \mathrm{ml}$ & 15 \\
\cline { 2 - 4 } & 5.00 & $250 \mathrm{ml}$ & 15 \\
\hline \multirow{4}{*}{ Speed } & 1.00 & Low & 25 \\
\cline { 2 - 4 } & 2.00 & Medium & 25 \\
\cline { 2 - 4 } & 3.00 & High & 25 \\
\hline
\end{tabular}

TABLE IV. DESCRIPTIVE STATISTICAL TEST RESUltS

\begin{tabular}{|c|c|c|c|c|}
\hline Load & Speed & Mean & $\begin{array}{c}\text { Std } \\
\text { Deviation }\end{array}$ & $\mathbf{N}$ \\
\hline \multirow{4}{*}{ Not Burdened } & Low & 2390,4 & 0,54772 & 5 \\
\hline & Medium & 2870,0 & 0,70711 & 5 \\
\hline & High & 3310,2 & 0,44721 & 5 \\
\hline & Total & 2856,86 & 388,8056 & 15 \\
\hline \multirow{4}{*}{$100 \mathrm{ml}$} & Low & 178,2 & 0,44721 & 5 \\
\hline & Medium & 233,0 & 0,0 & 5 \\
\hline & High & 266,6 & 0,54772 & 5 \\
\hline & Total & 225,933 & 37,71409 & 15 \\
\hline \multirow{4}{*}{$150 \mathrm{ml}$} & Low & 115,2 & 0,44721 & 5 \\
\hline & Medium & 210,8 & 0,44721 & 5 \\
\hline & High & 244,6 & 0,54772 & 5 \\
\hline & Total & 190,2 & 56,72389 & 15 \\
\hline \multirow{4}{*}{$200 \mathrm{ml}$} & Low & 111,2 & 0,44721 & 5 \\
\hline & Medium & 198,0 & 0,70711 & 5 \\
\hline & High & 230,2 & 0,44721 & 5 \\
\hline & Total & 179,8 & 52,02362 & 15 \\
\hline \multirow{4}{*}{$250 \mathrm{ml}$} & Low & 106,0 & 0,0 & 5 \\
\hline & Medium & 188,8 & 0,44721 & 5 \\
\hline & High & 215,8 & 0,44721 & 5 \\
\hline & Total & 170,2 & 48,35612 & 15 \\
\hline \multirow{4}{*}{ Total } & Low & 580,2 & 924,1528 & 25 \\
\hline & Medium & 740,12 & 1087,005 & 25 \\
\hline & High & 853,48 & 1253,806 & 25 \\
\hline & Total & 724,6 & 1087,562 & 75 \\
\hline
\end{tabular}

In this test, five tests were carried out on the load, such as unencumbered, with a load of $100 \mathrm{ml}, 150 \mathrm{ml}, 200 \mathrm{ml}$ and $500 \mathrm{ml}$. This tool is made using 3 speed options, namely low, 
medium and high. Descriptive test results are obtained as shown in Table 4.

In Table 4, it is found that when conditions are not burdened with a choice of low speed, the average motor rotation is $2390.40 \mathrm{rpm}$, with an average medium speed of $2870 \mathrm{rpm}$ motor rotation and with high speed motor rotation an average of $3310.20 \mathrm{rpm}$. Likewise, with the loading of $100 \mathrm{ml}, 150 \mathrm{ml}, 200 \mathrm{ml}$ and $250 \mathrm{ml}$.

Furthermore, the Tests of Between Subjects Effects test was performed. This test is carried out to get whether the data is normally distributed or not. The test results can be seen in Table 5. In this test, the results of the data are not normally distributed which is shown by the results of the load, speed, load and speed of less than 0.05 .

Next, the Homogeneous Subsets test was carried out. This test is carried out to determine whether the statistical data is homogeneous or not. This testing is done on the load and speed data. The test results are shown in Table 6.

TABLE V. TEST OF BETWEen SubJeCtS EFFECTS

\begin{tabular}{|c|c|c|c|c|c|}
\hline Source & $\begin{array}{c}\text { Type III } \\
\text { Sum of } \\
\text { Squares }\end{array}$ & DF & $\begin{array}{c}\text { Mean } \\
\text { Square }\end{array}$ & F & Signification \\
\hline $\begin{array}{c}\text { Corrected } \\
\text { Model }\end{array}$ & $\begin{array}{c}87525672,0 \\
\text { a }\end{array}$ & 11 & $\begin{array}{c}7956879,27 \\
3\end{array}$ & $\begin{array}{c}510471,8 \\
88\end{array}$ & 0,000 \\
\hline Intercept & $\begin{array}{c}50656474,2 \\
86\end{array}$ & 1 & $\begin{array}{c}50656474,2 \\
86\end{array}$ & $\begin{array}{c}3249855, \\
275\end{array}$ & 0,000 \\
\hline Load & $\begin{array}{c}85273878,9 \\
33\end{array}$ & 3 & $\begin{array}{c}28424626,3 \\
11\end{array}$ & $\begin{array}{c}1823575, \\
822\end{array}$ & 0,000 \\
\hline Speed & $\begin{array}{c}1109444,68 \\
6\end{array}$ & 2 & 554722,343 & $\begin{array}{c}35588,09 \\
3\end{array}$ & 0,000 \\
\hline $\begin{array}{c}\text { Load } * \\
\text { Speed }\end{array}$ & $\begin{array}{c}1309235,94 \\
7\end{array}$ & 6 & 218205,991 & $\begin{array}{c}13998,95 \\
9\end{array}$ & 0,000 \\
\hline Error & 982,0 & 63 & 15,587 & & \\
\hline Total & $\begin{array}{c}126905041, \\
0\end{array}$ & 75 & & & \\
\hline $\begin{array}{c}\text { Corrected } \\
\text { Total }\end{array}$ & $\begin{array}{c}87526654,0 \\
00\end{array}$ & 74 & & & \\
\hline a. R Squared $=1.000$ (Adjusted R Squared = 1.000) & \\
\hline
\end{tabular}

TABLE VI. HOMOGENOUS LOAD SUBSETS

\begin{tabular}{|l|c|c|c|c|c|}
\hline \multirow{2}{*}{ Load } & \multirow{2}{*}{ N } & \multicolumn{5}{|c|}{ Subset } \\
\cline { 3 - 6 } & & $\mathbf{1}$ & $\mathbf{2}$ & $\mathbf{3}$ & $\mathbf{4}$ \\
\hline $200 \mathrm{ml}$ & 15 & 170.2 & & & \\
\hline $150 \mathrm{ml}$ & 30 & & 185.0 & & \\
\hline $100 \mathrm{ml}$ & 15 & & & 225.9 & \\
\hline Not Burdened & 15 & & & & 2856.8 \\
\hline Sig & & 1.000 & 1.000 & 1.000 & 1.000 \\
\hline
\end{tabular}

At the load of homogenous subsets test results, the test values are in a different subset. At $200 \mathrm{ml}$ load, the value obtained is 170.2 , located in subset 1 , the $150 \mathrm{ml}$ load, the value obtained is 185.0 , is in subset 2 , the $100 \mathrm{ml}$ load, the value obtained is 225.9 , is located in subset 3 and when it is not burdened the value obtained 2856.8 is located in subset 4 . This shows that each load data is in a different subset and this means that the data is not homogeneous. The speed data test results are obtained as shown in Table 7.
TABLE VII. Homogenous SubSETS THE SPEED

\begin{tabular}{|c|c|c|c|c|}
\hline \multirow{2}{*}{ Speed } & \multirow{2}{*}{$\mathrm{N}$} & \multicolumn{3}{|c|}{ Subset } \\
\cline { 3 - 5 } & & 1 & 2 & 3 \\
\hline Low & 25 & 580,2 & & \\
\hline Medium & 25 & & 740,12 & \\
\hline High & 25 & & & 853,48 \\
\hline Sig & & 1,000 & 1,000 & 1,000 \\
\hline
\end{tabular}

At the load of homogenous subsets test results, the test values are in a different subset. At the low speed of 200 the value obtained 580.2 is located in subset 1 , the medium velocity value obtained is 740.12 is in subset 2 and the high velocity value obtained is 853.48 located in subset 3 . This shows in each speed data are in different subsets and this means the data is not homogeneous. In testing the tests of between subject's effects and homogeneous sub sets, the data results are not normally distributed and not homogeneous. For further testing, it was carried out using the Wilcoxon test.

In testing the homogeneity of the solution using a microcontroller based magnetic stirrer and the manufacturer's magnetic stirrer will compare the results of the resulting solution. In this test using the same mixing speed and the same stirring time. So the results obtained are homogeneous and not homogeneous, therefore for statistical testing used is the non-parametric Wilcoxon signed ranks test. Testing with solution $1,100 \mathrm{ml}$ water with $40 \mathrm{ml}$ syrup, obtained statistical test results as shown in Table 8. In the homogeneous test for solution 1 , the value of 1,000 is obtained where the value is greater than 0.05 . This means that there is no difference in the results of the solution between using a microcontroller based magnetic stirrer (digital) and a manufactured magnetic stirrer (analog).

Testing with solution $2,100 \mathrm{ml}$ water with $20 \mathrm{ml}$ special grade syrup, obtained statistical test results as shown in Table 9. In the homogeneous test for solution 2, the value of 1,000 was obtained where the value is greater than 0.05 . This means that there is no difference in the results of the solution between using a microcontroller based magnetic stirrer (digital) and a magnetic stirrer manufacturer (analog).

Testing with solution $3,100 \mathrm{ml}$ water with $40 \mathrm{ml}$ special grade syrup, obtained statistical test results as shown in Table 10. In the homogeneous test for solution 3 , the value was 0.000 , where the value was less than 0.05 . This means that there is a difference in results between using a microcontroller based magnetic stirrer (digital) and a magnetic stirrer manufacturer (analog).

Testing with solution $4,100 \mathrm{ml}$ water with $2.5 \mathrm{gr}$ salt, obtained the results of statistical tests as shown in Table 11. In the homogeny test for solution 4, a value of 1,000 was obtained where the value was greater than 0.05 . This means that there is no difference in the results of the solution between using a microcontroller based magnetic stirrer (digital) and the manufacturer's magnetic stirrer (analog). 
TABLE VIII. TESTING With SOLUTION 1

\begin{tabular}{|l|c|}
\hline & Digital - Analog \\
\hline$Z$ & $0,000^{\mathrm{b}}$ \\
\hline Asymp. Sig. (2-tailed) & 1,000 \\
\hline a. Wilcoxon Signed Ranks Test \\
\hline b. The sum of negative ranks equals the sum of positive ranks. \\
\hline
\end{tabular}

TABLE IX. TESTING WITH SOLUTION 2

\begin{tabular}{|l|c|}
\hline & Digital - Analog \\
\hline$Z$ & $0,000^{\mathrm{b}}$ \\
\hline Asymp. Sig. (2-tailed) & 1,000 \\
\hline a. Wilcoxon Signed Ranks Test \\
\hline b. The sum of negative ranks equals the sum of positive ranks. \\
\hline
\end{tabular}

TABLE X. Testing With Solution 3

\begin{tabular}{|l|c|}
\hline & Digital - Analog \\
\hline$Z$ & $-5,000^{\mathrm{b}}$ \\
\hline Asymp. Sig. (2-tailed) & 0,000 \\
\hline a. Wilcoxon Signed Ranks Test \\
\hline b. Based on positive ranks. \\
\hline
\end{tabular}

TABLE XI. TESTING With SOLUTION 4

\begin{tabular}{|l|c|}
\hline & Digital - Analog \\
\hline$Z$ & $0,000^{\mathrm{b}}$ \\
\hline Asymp. Sig. (2-tailed) & 1,000 \\
\hline a. Wilcoxon Signed Ranks Test \\
\hline b. The sum of negative ranks equals the sum of positive ranks. \\
\hline
\end{tabular}

TABLE XII. TESTING WITH SOLUTION 5

\begin{tabular}{|l|l|}
\hline & Digital - Analog \\
\hline $\mathrm{Z}$ & $0,000^{\mathrm{b}}$ \\
\hline Asymp. Sig. (2-tailed) & 1,000 \\
\hline a. Wilcoxon Signed Ranks Test \\
\hline b. The sum of negative ranks equals the sum of positive ranks. \\
\hline
\end{tabular}

Testing with solution $5,100 \mathrm{ml}$ water with $3.5 \mathrm{gr}$ salt, obtained the results of statistical tests as shown in Table 12. In the homogeny test for solution 5, the value of 1,000 was obtained where the value was greater than 0.05 . This means that there is no difference in the results of the solution between using a microcontroller based magnetic stirrer (digital) and the manufacturer's magnetic stirrer (analog).

Testing with solution $6,100 \mathrm{ml}$ water with $6.5 \mathrm{gr}$ salt, obtained the results of statistical tests as shown in Table 13. In the homogeny test for solution 6, a value of 1,000 was obtained where the value was greater than 0.05 . This means that there is no difference in the results of the solution between using a microcontroller based magnetic stirrer (digital) and the manufacturer's magnetic stirrer (analog).
TABLE XIII. TESTING WiTH SOLUTION 6

\begin{tabular}{|l|c|}
\hline & Digital - Analog \\
\hline$Z$ & $0,000^{\mathrm{b}}$ \\
\hline Asymp. Sig. (2-tailed) & 1,000 \\
\hline a. Wilcoxon Signed Ranks Test \\
\hline b. The sum of negative ranks equals the sum of positive ranks. \\
\hline
\end{tabular}

TABLE XIV. TESTING WITH SOLUTION 7

\begin{tabular}{|l|c|}
\hline & Digital - Analog \\
\hline$Z$ & $-6,708^{\mathrm{b}}$ \\
\hline Asymp. Sig. (2-tailed) & 0,000 \\
\hline a. Wilcoxon Signed Ranks Test \\
\hline b. Based on positive ranks. \\
\hline
\end{tabular}

TABLE XV. TESTING WiTH SOLUTION 8

\begin{tabular}{|l|c|}
\hline & Digital - Analog \\
\hline$Z$ & $-4,472^{\mathrm{b}}$ \\
\hline Asymp. Sig. (2-tailed) & 0,000 \\
\hline a. Wilcoxon Signed Ranks Test \\
\hline b. Based on positive ranks. \\
\hline
\end{tabular}

TABLE XVI. TESTING With SOLUTION 9

\begin{tabular}{|l|c|}
\hline & Digital - Analog \\
\hline$Z$ & $-5,000^{\mathrm{b}}$ \\
\hline Asymp. Sig. (2-tailed) & 0,000 \\
\hline a. Wilcoxon Signed Ranks Test \\
\hline b. Based on positive ranks. \\
\hline
\end{tabular}

Testing with solution $7,100 \mathrm{ml}$ water with $10 \mathrm{gr}$ salt, obtained the results of statistical tests as shown in Table 14. In the homogeny test for solution 7 , the value was 0.000 , which is less than 0.05 . This means that there is a difference in the results of the solution between using a microcontroller based magnetic stirrer (digital) and a manufactured magnetic stirrer (analog).

Testing with solution $8,100 \mathrm{ml}$ water with $2.5 \mathrm{gr}$ sugar, obtained the results of statistical testing as shown in Table 15. In the homogeneous test for solution 8 , the value was 0.000 , which is less than 0.05 . This means that there is a difference in the results of the solution between using a microcontroller based magnetic stirrer (digital) and a magnetic stirrer manufacturer (analog).

Testing with solution $9,100 \mathrm{ml}$ water with $3.5 \mathrm{gr}$ sugar, obtained the results of statistical tests as shown in Table 16. In the homogeny test for solution 9, the value was 0.000 , which is less than 0.05 . This means that there is a difference in the results of the solution between using a microcontroller based magnetic stirrer (digital) and a manufactured magnetic stirrer (analog). 
Testing with solution $10,100 \mathrm{ml}$ water with $6.5 \mathrm{gr}$ sugar, obtained the results of statistical tests as shown in Table 17. In the homogeny test for solution 10 , the value was 0.000 where the value was less than 0.05 . This means that there is a difference in the results of the solution between using a microcontroller based magnetic stirrer (digital) and a magnetic stirrer manufacturer (analog).

Testing with solution $11,100 \mathrm{ml}$ water with $10 \mathrm{gr}$ of sugar, obtained the results of statistical testing as shown in Table 18. In the homogeneous test for solution 11 , the value was 0.000 , where the value was less than 0.05 . This means that there is a difference in the results of the solution between using a microcontroller based magnetic stirrer (digital) and a magnetic stirrer manufacturer (analog).

TABLE XVII. TESTING WITH SOLUTION 10

\begin{tabular}{|l|c|}
\hline & Digital - Analog \\
\hline$Z$ & $-3,873^{\mathrm{b}}$ \\
\hline Asymp. Sig. (2-tailed) & 0,000 \\
\hline a. Wilcoxon Signed Ranks Test \\
\hline b. Based on positive ranks. \\
\hline
\end{tabular}

TABLE XVIII. TESTING WITH SOLUTION 11

\begin{tabular}{|l|c|}
\hline & Digital - Analog \\
\hline$Z$ & $-3,873^{\mathrm{b}}$ \\
\hline Asymp. Sig. (2-tailed) & 0,000 \\
\hline a. Wilcoxon Signed Ranks Test \\
\hline b. Based on positive ranks. \\
\hline
\end{tabular}

TABLE XIX. RESUlt OF STATISTICAL TESTING OF A MiCROCONTROLlER BASED MAGNETIC STIRRER WITH A MANUFACTURER's MAGNETIC STIRRER

\begin{tabular}{|c|c|c|c|}
\hline No. & Solution & $\begin{array}{c}\text { Value of } \\
\text { Significance }\end{array}$ & $\begin{array}{c}\text { Analog and } \\
\text { Digital } \\
\text { Comparison }\end{array}$ \\
\hline 1. & Solution 1 & 1,000 & No \\
\hline 2. & Solution 2 & 1,000 & No \\
\hline 3. & Solution 3 & 0,00 & Yes \\
\hline 4. & Solution 4 & 1,000 & No \\
\hline 5. & Solution 5 & 1,000 & No \\
\hline 6. & Solution 6 & 1,000 & No \\
\hline 7. & Solution 7 & 0,00 & Yes \\
\hline 8. & Solution 8 & 0,00 & Yes \\
\hline 9. & Solution 9 & 0,00 & Yes \\
\hline 10. & Solution 10 & 0,00 & Yes \\
\hline 11. & Solution 11 & 0,00 & Yes \\
\hline
\end{tabular}

Based on the results of statistical tests using the nonparametric Wilcoxon signed ranks test, which was tested on 11 solutions, the significance value was obtained according to Table 19.

In solutions $1,2,4,5$ and 6 there is no difference in producing a homogeneous solution using a microcontroller based magnetic stirrer compared to the manufacturer's magnetic stirrer. For solutions 1,2,4,5 and 6 with low, medium and high speeds within 1-15 minutes can produce a homogeneous solution. For the test results on all types of solutions using a microcontroller based magnetic stirrer in Figure 2. From 132 experiments with mixing times of 1, 5, 10 , and 15 minutes, $75 \%$ of the solution can produce a homogeneous solution.

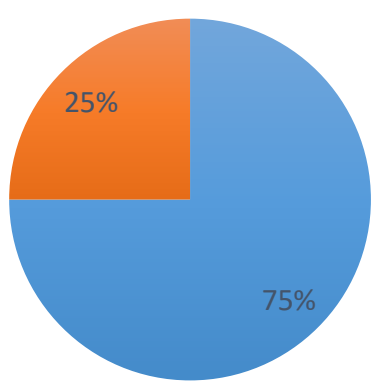

Homogeneous Solution Nonhomogeneous Solution

Fig. 2. Result of Testing the Solution Using a Microcontroller Based Magnetic Stirrer

Based on the results of statistical testing and solution testing using a microcontroller based magnetic stirrer in a solution with low viscosity with water mixing with syrup, it takes 1 minute to mix with low, medium and high speeds. For a water solution with special grade syrup for solutions with higher viscosity, it takes 5 minutes at medium and high speeds. To mix water with salt and water with sugar it takes 10 minutes at high speed.

The results of the non-parametric Wilcoxon signed ranks test which were tested on 11 solutions showed that in solutions 1, 2, 4, 5 and 6 there was no difference in producing a homogeneous solution using a microcontroller based magnetic stirrer compared to the manufacturer's magnetic stirrer. For solutions 1, 2, 4, 5 and 6 with low, medium and high velocities within 1 minute can produce a homogeneous yield. For homogeneity results in all types of solutions using a microcontroller based magnetic stirrer and a manufacturer's magnetic stirrer can be seen in Table 20.

There is a difference between digital and analog from Table 20. In solution 3, $100 \mathrm{ml}$ water with $40 \mathrm{ml}$ special grade syrup using a microcontroller based magnetic stirrer requires a minimum mixing time of 5 minutes at medium speed and 1 minute for high speed. Meanwhile, magnetic stirrers with analog speed settings require a minimum mixing time of 1 minute at low, medium and high speeds. This difference is caused by the manufacturer's magnetic stirrer with the analog speed setting at any speed in the initial 30 seconds the rotation speed is in high condition and after 30 seconds the speed is constant according to the set speed. For solutions 7, 8, 9, 10 and 11 the results are in accordance with Table 21. Testing with 11 solutions with different viscosity solutions using a microcontroller based magnetic stirrer and a magnetic stirrer manufacturer can produce a homogeneous solution. 
TABLE XX. RESUlt OF HomOgEnEITY TEST OF SOLUTION

\begin{tabular}{|c|c|c|c|c|c|c|c|c|c|c|c|c|}
\hline \multirow{2}{*}{ No } & \multirow{2}{*}{ Solution } & \multirow{2}{*}{ Significant } & \multirow{2}{*}{$\begin{array}{c}\text { Analog - Digital } \\
\text { Comparison }\end{array}$} & \multirow{2}{*}{ Speed } & \multicolumn{4}{|c|}{ Analog Time } & \multicolumn{4}{|c|}{ Digital Time } \\
\hline & & & & & 1 & 5 & 10 & 15 & 1 & 5 & 10 & 15 \\
\hline \multirow{3}{*}{1.} & \multirow{3}{*}{ Solution 1} & \multirow{3}{*}{1,000} & \multirow{3}{*}{ No } & Low & $\sqrt{ }$ & $\sqrt{ }$ & $\sqrt{ }$ & $\sqrt{ }$ & $\sqrt{ }$ & $\sqrt{ }$ & $\sqrt{ }$ & $\sqrt{ }$ \\
\hline & & & & Medium & $\sqrt{ }$ & $\sqrt{ }$ & $\sqrt{ }$ & $\sqrt{ }$ & $\sqrt{ }$ & $\sqrt{ }$ & $\sqrt{ }$ & $\sqrt{ }$ \\
\hline & & & & High & $\sqrt{ }$ & $\sqrt{ }$ & $\sqrt{ }$ & $\sqrt{ }$ & $\sqrt{ }$ & $\sqrt{ }$ & $\sqrt{ }$ & $\sqrt{ }$ \\
\hline \multirow{3}{*}{2.} & \multirow{3}{*}{ Solution 2} & \multirow{3}{*}{1,000} & \multirow{3}{*}{ No } & Low & $\sqrt{ }$ & $\sqrt{ }$ & $\sqrt{ }$ & $\sqrt{ }$ & $\sqrt{ }$ & $\sqrt{ }$ & $\sqrt{ }$ & $\sqrt{ }$ \\
\hline & & & & Medium & $\sqrt{ }$ & $\sqrt{ }$ & $\sqrt{ }$ & $\sqrt{ }$ & $\sqrt{ }$ & $\sqrt{ }$ & $\sqrt{ }$ & $\sqrt{ }$ \\
\hline & & & & High & $\sqrt{ }$ & $\sqrt{ }$ & $\sqrt{ }$ & $\sqrt{ }$ & $\sqrt{ }$ & $\sqrt{ }$ & $\sqrt{ }$ & $\sqrt{ }$ \\
\hline \multirow{3}{*}{3.} & \multirow{3}{*}{ Solution 3} & \multirow{3}{*}{0,00} & \multirow{3}{*}{ Yes } & Low & $\sqrt{ }$ & $\sqrt{ }$ & $\sqrt{ }$ & $\sqrt{ }$ & $\mathrm{X}$ & $\mathrm{X}$ & $\mathrm{X}$ & $\mathrm{X}$ \\
\hline & & & & Medium & $\sqrt{ }$ & $\sqrt{ }$ & $\sqrt{ }$ & $\sqrt{ }$ & $\mathrm{X}$ & $\sqrt{ }$ & $\sqrt{ }$ & $\sqrt{ }$ \\
\hline & & & & High & $\sqrt{ }$ & $\sqrt{ }$ & $\sqrt{ }$ & $\sqrt{ }$ & $\sqrt{ }$ & $\sqrt{ }$ & $\sqrt{ }$ & $\sqrt{ }$ \\
\hline \multirow{3}{*}{4.} & \multirow{3}{*}{ Solution 4} & \multirow{3}{*}{1,000} & \multirow{3}{*}{ No } & Low & $\sqrt{ }$ & $\sqrt{ }$ & $\sqrt{ }$ & $\sqrt{ }$ & $\sqrt{ }$ & $\sqrt{ }$ & $\sqrt{ }$ & $\sqrt{ }$ \\
\hline & & & & Medium & $\sqrt{ }$ & $\sqrt{ }$ & $\sqrt{ }$ & $\sqrt{ }$ & $\sqrt{ }$ & $\sqrt{ }$ & $\sqrt{ }$ & $\sqrt{ }$ \\
\hline & & & & High & $\sqrt{ }$ & $\sqrt{ }$ & $\sqrt{ }$ & $\sqrt{ }$ & $\sqrt{ }$ & $\sqrt{ }$ & $\sqrt{ }$ & $\sqrt{ }$ \\
\hline \multirow{3}{*}{5.} & \multirow{3}{*}{ Solution 5} & & & Low & $\sqrt{ }$ & $\sqrt{ }$ & $\sqrt{ }$ & $\sqrt{ }$ & $\sqrt{ }$ & $\sqrt{ }$ & $\sqrt{ }$ & $\sqrt{ }$ \\
\hline & & 1,000 & No & Medium & $\sqrt{ }$ & $\sqrt{ }$ & $\sqrt{ }$ & $\sqrt{ }$ & $\sqrt{ }$ & $\sqrt{ }$ & $\sqrt{ }$ & $\sqrt{ }$ \\
\hline & & & & High & $\sqrt{ }$ & $\sqrt{ }$ & $\sqrt{ }$ & $\sqrt{ }$ & $\sqrt{ }$ & $\sqrt{ }$ & $\sqrt{ }$ & $\sqrt{ }$ \\
\hline & & & & Low & $\sqrt{ }$ & $\sqrt{ }$ & $\sqrt{ }$ & $\sqrt{ }$ & $\sqrt{ }$ & $\sqrt{ }$ & $\sqrt{ }$ & $\sqrt{ }$ \\
\hline 6. & Solution 6 & 1,000 & No & Medium & $\sqrt{ }$ & $\sqrt{ }$ & $\sqrt{ }$ & $\sqrt{ }$ & $\sqrt{ }$ & $\sqrt{ }$ & $\sqrt{ }$ & $\sqrt{ }$ \\
\hline & & & & High & $\sqrt{ }$ & $\sqrt{ }$ & $\sqrt{ }$ & $\sqrt{ }$ & $\sqrt{ }$ & $\sqrt{ }$ & $\sqrt{ }$ & $\sqrt{ }$ \\
\hline & & & & Low & $\sqrt{ }$ & $\sqrt{ }$ & $\sqrt{ }$ & $\sqrt{ }$ & $\mathrm{X}$ & $\mathrm{X}$ & $\mathrm{X}$ & $\mathrm{X}$ \\
\hline 7. & Solution 7 & 0,00 & Yes & Medium & $\sqrt{ }$ & $\sqrt{ }$ & $\sqrt{ }$ & $\sqrt{ }$ & $\mathrm{X}$ & $\mathrm{X}$ & $\mathrm{X}$ & $\mathrm{X}$ \\
\hline & & & & High & $\sqrt{ }$ & $\sqrt{ }$ & $\sqrt{ }$ & $\sqrt{ }$ & $\mathrm{X}$ & $\sqrt{ }$ & $\sqrt{ }$ & $\sqrt{ }$ \\
\hline & & & & Low & $\mathrm{X}$ & $\sqrt{ }$ & $\sqrt{ }$ & $\sqrt{ }$ & $\mathrm{X}$ & $\mathrm{X}$ & $\mathrm{X}$ & $\mathrm{X}$ \\
\hline 8. & Solution 8 & 0,00 & Yes & Medium & $\sqrt{ }$ & $\sqrt{ }$ & $\sqrt{ }$ & $\sqrt{ }$ & $\mathrm{X}$ & $\sqrt{ }$ & $\sqrt{ }$ & $\sqrt{ }$ \\
\hline & & & & High & $\sqrt{ }$ & $\sqrt{ }$ & $\sqrt{ }$ & $\sqrt{ }$ & $\sqrt{ }$ & $\sqrt{ }$ & $\sqrt{ }$ & $\sqrt{ }$ \\
\hline & & & & Low & $\mathrm{X}$ & $\sqrt{ }$ & $\sqrt{ }$ & $\sqrt{ }$ & $\mathrm{X}$ & $\mathrm{X}$ & $\mathrm{X}$ & $\mathrm{X}$ \\
\hline 9. & Solution 9 & 0,00 & Yes & Medium & $\sqrt{ }$ & $\sqrt{ }$ & $\sqrt{ }$ & $\sqrt{ }$ & $\mathrm{X}$ & $\sqrt{ }$ & $\sqrt{ }$ & $\sqrt{ }$ \\
\hline & & & & High & $\sqrt{ }$ & $\sqrt{ }$ & $\sqrt{ }$ & $\sqrt{ }$ & $\mathrm{X}$ & $\sqrt{ }$ & $\sqrt{ }$ & $\sqrt{ }$ \\
\hline & & & & Low & $\mathrm{X}$ & $\sqrt{ }$ & $\sqrt{ }$ & $\sqrt{ }$ & $\mathrm{X}$ & $\mathrm{X}$ & $\mathrm{X}$ & $\mathrm{X}$ \\
\hline 10. & Solution 10 & 0,00 & Yes & Medium & $X$ & $\sqrt{ }$ & $\sqrt{ }$ & $\sqrt{ }$ & $\mathrm{X}$ & $\sqrt{ }$ & $\sqrt{ }$ & $\sqrt{ }$ \\
\hline & & & & High & $\mathrm{X}$ & $\sqrt{ }$ & $\sqrt{ }$ & $\sqrt{ }$ & $\mathrm{X}$ & $\sqrt{ }$ & $\sqrt{ }$ & $\sqrt{ }$ \\
\hline & & & & Low & $X$ & $X$ & $\sqrt{ }$ & $\sqrt{ }$ & X & $\mathrm{X}$ & $\mathrm{X}$ & $\mathrm{X}$ \\
\hline 11. & Solution 11 & 0,00 & Yes & Medium & $\mathrm{X}$ & $\mathrm{X}$ & $\sqrt{ }$ & $\sqrt{ }$ & $\mathrm{X}$ & $\mathrm{X}$ & $\sqrt{ }$ & $\sqrt{ }$ \\
\hline & & & & High & $\mathrm{X}$ & $\sqrt{ }$ & $\sqrt{ }$ & $\sqrt{ }$ & $\mathrm{X}$ & $\sqrt{ }$ & $\sqrt{ }$ & $\sqrt{ }$ \\
\hline
\end{tabular}

\section{CONCLUSION}

Microcontroller based magnetic stirrer in a solution with low viscosity by mixing water with syrup requires mixing for 1 minute at low, medium and high speeds. For a water solution with special grade syrup for solutions with higher viscosity, it takes 5 minutes at medium and high speeds. To mix water with salt and water with sugar, it takes 10 minutes at high speed. Microcontroller based magnetic stirrer and manufacturer's magnetic stirrer can produce a homogeneous solution.

\section{REFERENCES}

[1] Y-W. Tang, J. E. Schmitz, D. H. Persing, and C. W. Stratton "Laboratory diagnosis of COVID-19: current issues and challenges," Journal of clinical microbiology, vol. 58, no. 6, pp. 1-9, 2020.

[2] G. Lippi and M. Plebani, "Laboratory abnormalities in patients with COVID-2019 infection," Clinical Chemistry and Laboratory Medicine (CCLM), vol. vol. 58, no. 7, pp. 1131-1134, 2020.

[3] A. J. Rodriguez-Morales et al., "Clinical, laboratory and imaging features of COVID-19: A systematic review and meta-analysis," Travel Med. Infect. Dis., vol. 34, p. 101623, Mar. 2020, doi: 10.1016/J.TMAID.2020.101623. 
[4] M. J. Loeffelholz and Y-W. Tang, "Laboratory diagnosis of emerging human coronavirus infections-the state of the art," Emerging microbes \& infections, vol. 9, no. 1, pp. 747-756, 2020.

[5] Y. Gao, T. Li, M. Han, X. Li, D. Wu, Y. Xu, Y. Zhu, Y. Liu, X. Wang, L. Wang, "Diagnostic utility of clinical laboratory data determinations for patients with the severe COVID-19," Journal of medical virology vol. 92, no. 7, pp. 791-796 2020.

[6] M. M. Azar, and A. H. Chadi, "Laboratory diagnostics for histoplasmosis," Journal of clinical microbiology, vol. 55, no. 6, pp. 1612-1620, 2017.

[7] Lowrie, P. E. W. "Mitzubishi Cyclon," Proceeding of Electrolytic Gas, USA, 2005.

[8] D. Dange, A. R. Gair, D. D. L. Jones, M. Juckel, S. Aldridge, and C. Jones, "Acyclic 1,2-dimagnesioethanes/-ethene derived from magnesium (i) compounds: multipurpose reagents for organometallic synthesis," Chemical science, vol. 10, no. 11, pp. 3208-3216, 2019.

[9] B. Chen and X. F. Wu, "Palladium-Catalyzed Synthesis of 1, 2Diketones from Aryl Halides and Organoaluminum Reagents Using tert-Butyl Isocyanide as the CO Source," Organic letters, vol. 22, no. 2, pp. 636-641, 2020.

[10] J. S. Compton, B. Saeednia, C. B. Kelly, and G. A. Molander, "3Boryl-2, 1-borazaronaphthalene: Umpolung Reagents for Diversifying Naphthalene Isosteres," The Journal of organic chemistry, vol. 83, no. 16, pp. 9484-9491, 2018.

[11] M. A. Bezerra, V. A. Lemos, C. G. Novaes, R. M. Jesus, H. R. S. Filho, S. A. Araújo, J. P. S. Alves, "Application of mixture design in analytical chemistry," Microchemical Journal, vol. 152, 2020.

[12] J. E. Hales, S. Aoudjane, G. Aeppli, and P. A. Dalby, "Proof-ofconcept analytical instrument for label-free optical deconvolution of protein species in a mixture," Journal of Chromatography A, 2021, 1641: 461968

[13] A. Subratti, L. J. Lalgee, and N. K. Jalsa. "Robust, Efficient, and Economical Magnetic Stirrer: A Device Based on Pulsed Width Modulation, Built Using Mainly Recycled Parts," Journal of Chemical Education, vol. 97, no. 1, pp. 305-3-7, 2019.

[14] N. Mahmoodi, "Are reported methods for synthesizing nanoparticles and microparticles by magnetic stirrer reproducible," Journal of Computational Applied Mechanics, vol. 51, no. 2, pp. 498-500, 2020.

[15] S. Salisu "Design and Fabrication of a Magnetic Stirrer for Bio-Diesel Production," FUPRE Journal of Scientific and Industrial Research (FJSIR), vol. 4, no. 1, pp. 36-49, 2020.

[16] D. Cai, P. S. Clegg, T. Li, K. A. Rumble, and J.W. Tavacoil, "Bijels formed by direct mixing," Soft Matter, vol. 13, no. 28, pp. 4824-4829, 2017.

[17] A. M. Scholl, E. Pozio, J. Gayda, N. Thaben, P. Bahn, and K. Nockler, "Magnetic stirrer method for the detection of Trichinella larvae in muscle samples," JoVE (Journal of Visualized Experiments), 2017.

[18] M. Rebosura Jr., S. Salehin, I. Pikaar, X. Sun, J. Keller, K. Sharma, and Z. Yuan "A comprehensive laboratory assessment of the effects of sewer-dosed iron salts on wastewater treatment processes," Water research, vol. 146, pp. 109-117, 2018.

[19] S. Jokić, K. Aladić, and D. Šubarić. "Subcritical water extraction laboratory plant design and application," Annual of the Croatian Academy of Engineering, vol. 21, pp. 247-258, 2018.

[20] R. Kincaid and G. Pollock, "Nicky: Toward a Virtual Assistant for Test and Measurement Instrument Recommendations," 2017 IEEE 11 th International Conference on Semantic Computing (ICSC), 2017, pp. 196-203, doi: 10.1109/ICSC.2017.11.

[21] H, Lv, "Digital Multimeter Automatic Verification Device Design," Genetic and Evolutionary Computing: Proceedings of the Thirteenth International Conference on Genetic and Evolutionary Computing, November 1-3, 2019, Qingdao, China, vol. 1107, Springer Nature, 2020

[22] D. Galar and U. Kumar, eMaintenance: Essential electronic tools for efficiency, Academic Press, 2017.

[23] A. O. Oyedeji, "Development of an Arduino Based Electric Cooker Timer System," JITCE (Journal of Information Technology and Computer Engineering), vol. 4, no. 1, pp. 28-31, 2020.

[24] R. H. Ali, M. Rahmad, N. Islami, Azizahwati and M. Syafii, "Design of Straight Motion Experiment using Electric Motor Ticker Timer Based on Microcontroller," Journal of Physics: Conference Series, vol. 1655, no. 1, IOP Publishing, 2020.

[25] R. Waswani, A. Pawar, M. Deore and R. Patel, "Induction motor fault detection, protection and speed control using arduino," 2017 International Conference on Innovations in Information, Embedded and Communication Systems (ICIIECS), 2017, pp. 1-5, doi: 10.1109/ICIIECS.2017.8276071.
[26] K. R. Asha, P. S. Tasleem, A. V. Ravi Kumar, S. M. Swamy and K. R. Rekha, "Real Time Speed Control of a DC Motor by Temperature Variation Using LabVIEW and Arduino," 2017 International Conference on Recent Advances in Electronics and Communication Technology (ICRAECT), 2017, pp. 72-75, doi: 10.1109/ICRAECT.2017.50.

[27] N. H. Wijaya, D. F. Novela, N. Shahu, M. U. Sattar "Arduino-based Mini Shaker for Automatic Chemical Solution Mixer," Journal of Robotics and Control (JRC), vol. 1, no. 6, pp. 220-223, 2020.

[28] E. C. Abana, M. Pacion, R. Sordilla, D. Montaner, D. Agpaoa, R. M. Allam "Rakebot: a robotic rake for mixing paddy in sun drying," Indonesian Journal of Electrical Engineering and Computer Science (IJEECS), vol. 14, no. 3, pp. 1165-1170, 2019.

[29] H. Xu, J. Liu, J. Zhang, G. Zhou, N. Luo, N. Zhao, "Flexible organic/inorganic hybrid near-infrared photoplethysmogram sensor for cardiovascular monitoring," Advanced Materials, vol. 29, no. 31, 2017.

[30] T. P. Tunggal, L. A. Kirana, A. Z. Arfianto, E. T. Helmy, F. Waseel, "The design of tachometer contact and non-contact using microcontroller," Journal of Robotics and Control (JRC), vol. 1, no. 3, pp. 65-69, 2020.

[31] Z. Tir, O. Malik, M. A. Hamida, H. Cherif, Y. Bekakra and A. Kadrine, "Implementation of a fuzzy logic speed controller for a permanent magnet dc motor using a low-cost Arduino platform," 2017 5th International Conference on Electrical Engineering - Boumerdes (ICEE-B), 2017, pp. 1-4, doi: 10.1109/ICEE-B.2017.8192218. 